\title{
O Atendimento Educacional Especializado para Altas Habilidades/Superdotação: das políticas à prática
}

\author{
Specialized Educational Service for High \\ Skills/Giftedness: from policies to practice
}

La asistencia educativa especializada para Altas Habilidades/

Superdotación: desde las politicas à las practicas

MARIA LÍDIA SICA SZYMANSKI ${ }^{\text {a id }}$

SANDRA Mara MACIEL VIEIRA ${ }^{b}(i D$

\section{Resumo}

O Atendimento Educacional Especializado para Altas Habilidades/Superdotação em Sala de Recursos Multifuncional e em sala de aula regular aos sujeitos que apresentam indicativos de Altas Habilidades/Superdotação é direito garantido por leis federais e estaduais. Assim, nesta pesquisa qualitativa e de campo indaga-se, frente às políticas públicas vigentes para a Educação Especial, quais as condições históricas e pedagógicas do Atendimento Educacional Especializado nas Salas de Recursos Multifuncionais para Altas Habilidades/Superdotação. Para resgatar a história, no Núcleo Regional de Educação de Cascavel, entrevistaram-se diretores e professores que iniciaram ou mantêm esse trabalho, e aplicaram-se questionários aos pais e alunos de uma Sala de Recursos Multifuncional, utilizando a Análise de Conteúdo para reflexão sobre os dados coletados. Os resultados revelaram dificuldades na identificação destes sujeitos. Aspectos como a precariedade na formação docente inicial e continuada, bem como a fragilidade nos critérios para a contratação de profissionais preparados e a falta de investimento estatal nas Salas de Recursos Multifuncionais, obstaculizam a continuidade no trabalho. É de suma

\footnotetext{
a Universidade Estadual do Oeste do Paraná, Cascavel, Paraná, Brasil. Doutora em Psicologia. E-mail: Szymanski_@hotmail.com

b Universidade Estadual do Oeste do Paraná, Cascavel, Paraná, Brasil. Mestre em Educação. E-mail: sandramaramv@hotmail.com
} 
importância que a Universidade amplie o trabalho conjunto com a Educação Básica e contribua com pesquisas e trabalhos de extensão junto à comunidade, também na área de Altas Habilidades/Superdotação. Entende-se que a escola tem o compromisso de propiciar a todos seus alunos o máximo desenvolvimento, além de uma leitura de mundo que lhes possibilite inserirem-se e contribuírem socialmente promovendo transformações visando uma sociedade mais justa e menos excludente.

Palavras-chave: Altas Habilidades/Superdotação. Atendimento Educacional Especializado. Educação Especial. Políticas públicas.

\begin{abstract}
Specialized educational service for gifted students in a Multifunctional Resources Classroom and in a regular classroom is a right guaranteed by federal and state laws. Thus, in this qualitative and field research it is asked which are the historical and pedagogical conditions of Specialized Educational Assistance (SEA) in a Multifunctional Resources Classroom for High Abilities/Giftedness. To rescue the history, in the Regional Education Center of Cascavel, directors and teachers, who had started this work, were or are part of the Specialized Educational Service, were interviewed and questionnaires were applied to parents and students of one Multifunctional Resources Classroom, using Content Analysis to enable reflections on the collected data. The results revealed difficulties in identifying these students. In addition, aspects such as the precariousness of initial and continuing teacher education, as well as the weakness in the criteria for hiring prepared professionals and the lack of state investment in Multifunctional Resources Classroom, hinder continuity in the work. It is of utmost importance that the University extends its joint work with the Basic Education and contributes to research, and extension with the community, also in the area of High Ability/Giftedness. The school must be committed to ensuring that all its students achieve maximum development. Besides, the students must be prepared for a reading of the world that allows them to be socially inserted, contributing to transformations aiming at a fairer and less discriminatory social process.
\end{abstract}

Keywords: High Skills/Giftedness. Specialized Educational Service. Special education. Public policies.

\title{
Resumen
}

La Asistencia Educativa Especializada (AEE) a los estudiantes que tienen indicativos de Altas Habilidades / Superdotación en una clase de recursos multifuncionales y en una clase regular es un derecho garantizado por las leyes federales y estatales. Para reflexionar sobre este servicio, se preguntó qué condiciones enfrentan los profesionales y estudiantes ante las políticas públicas vigentes. Para rescatar la historia, en el Núcleo Regional de Enseñanza de Cascavel (PR), se entrevistó a directores y docentes que habían iniciado este trabajo, eran o son parte de la Asistencia Educativa Especializada 
(AEE), y se les aplicaron cuestionarios a padres y alumnos de una Clase de Recursos Multifuncionales, utilizando Análisis de Contenido para permitir reflexiones sobre los datos recopilados. Los resultados revelaron dificultades para identificar estudiantes con AH/SD. Además, aspectos como la precariedad de la formación docente inicial y continua, así como la debilidad en los criterios de contratación de profesionales y la falta de inversión estatal en clases de recursos multifuncionales dificultan la continuidad en el trabajo. La escuela debe comprometerse a garantizar que todos sus estudiantes logren el máximo desarrollo. Es sumamente importante que la Universidad amplíe su acción conjunta con la Educación Básica y ocupe su rol en el desarrollo del labor de investigación y la extensión en la comunidad, también en el área de AH / SD, entendiendo que la escuela tiene un compromiso con la formación a todos sus alumnos para su máximo desarrollo. Es sumamente importante que la Universidad amplíe su acción conjunta con la Educación Básica y ocupe su rol en el desarollo de la investigación y extensión en la comunidad, también en el área de AH / SD. Si entiende que la escuela debe comprometerse a que todos sus alumnos logren el máximo desarrollo. Además, los estudiantes deben estar preparados para una lectura del mundo que permita su inserción social, contribuyendo a las transformaciones que conduzcan a un proceso social más justo y menos discriminatorio.

Palabras-clave: Altas Habilidades/Superdotación. Servicio educativo especializado. Educación especial. Políticas publicas.

\section{Introdução}

O presente artigo objetiva analisar as condições históricas e pedagógicas do Atendimento Educacional Especializado (AEE) nas salas de recursos multifuncionais (SRM) para Altas Habilidades/Superdotação (AH/SD), e refletir sobre a realidade atual deste atendimento, tomando-se como base o Núcleo Regional de Educação de Cascavel-PR (NRE/Cascavel -PR).

Justifica-se pela relevância do tema, e por não se ter encontrado nenhum outro documento que trate do registro histórico ou atual deste atendimento dentro da Educação Especial no NRE de Cascavel. Essa invisibilidade, aliada ao desconhecimento deste assunto, acarreta a invisibilidade desses sujeitos, e o consequente não atendimento especializado, o que pode gerar prejuízos acadêmicos e pessoais a esses estudantes, que têm direito a um amparo legal.

Inicia-se apresentando os fundamentos do desenvolvimento psíquico na perspectiva da Teoria Histórico Cultural. A seguir, destaca-se o que está previsto nas leis que conceituam e amparam o aluno com indicativos de AH/SD. 
Para investigar qual a realidade do AEE para AH/SD apresenta-se, então, uma pesquisa de campo, na qual entrevistaram-se diretores e professores que atuaram ou atuam em SRM para $\mathrm{AH} / \mathrm{SD}$ e aplicou-se um questionário a pais e alunos que frequentavam uma SRM para $\mathrm{AH} / \mathrm{SD}$ na cidade Cascavel/PR.

Com estes subsídios, finaliza-se discutindo se as políticas públicas vigentes estão reconhecendo o direito do AEE ao aluno com AH/SD, possibilitando-lhe, assim como a todos os que chegam à escola, a formação do pensamento teórico, e, portanto, o desenvolvimento máximo de suas funções psíquicas.

\section{Os Fundamentos da Teoria Histórico-Cultural}

Compreende-se o desenvolvimento humano na perspectiva da Teoria Histórico-Cultural, vertente crítica com potencial transformador, que se iniciou liderada por Lev Semionovitch Vigotski (1896-1927), e seus colaboradores Alexander Romanovich Luria (1902-1977) e Alexei Nikolaevich Leontiev (19031979), fundamentando-se, do ponto de vista filosófico, epistemológico e metodológico, no materialismo histórico dialético. Compactua-se com essa concepção de homem, de sociedade e de mundo e considera-se que é esta a teoria que melhor dialoga com a realidade concreta, pois permite a compreensão de que o homem é seu produto e produtor engendrando a totalidade que abarca a produção material e imaterial humana, possibilitando sua sobrevivência e vivência.

Nessa perspectiva, destaca-se a problemática das políticas públicas voltadas à educação, sobretudo à Educação Especial, e seus desdobramentos para uma educação que tenha como norte um viés emancipatório.

O desenvolvimento humano ocorre condicionado às relações sociais e ao contexto sócio histórico do qual o sujeito é partícipe, por meio de sua atividade vital, o trabalho. Por meio do trabalho, o homem transforma a natureza e reciprocamente transforma-se, desenvolvendo suas funções psicológicas superiores (FPS). Ou seja, para sobreviver, é necessário que o homem busque o que lhe falta, isto é, execute as ações e operações que sua situação humana lhe exige. Conforme ele se apropria dessas novas aquisições com as quais pretende satisfazer essa demanda, altera seu entorno e a si próprio. 
Esse desenvolvimento ocorre simultaneamente em duas vias: externa e interna. Na medida em que se apropria da cultura, o homem apropria-se do manuseio dos instrumentos e técnicas necessários à execução de suas atividades. Simultaneamente, suas ações e operações externas articulam-se ao desenvolvimento de seu sistema psíquico internamente, pois, sendo um processo acompanhado por palavras, essas palavras, na medida em que adquirem um significado para o sujeito, constituem-se na unidade que articula o pensamento e a linguagem (VYGOTSKY, 1991), e permitem que as ações e operações externas sejam representadas mentalmente, possibilitando o pensamento.

Trata-se de um processo que mobiliza e desenvolve o conjunto das funções psicológicas superiores, como atenção, percepção e memória, ligadas a esses novos significados, atuando como um feixe, de forma integrada. Esse processo carece de mediação para o seu pleno desenvolvimento, o qual não resulta de uma complexificação natural e evolutiva das funções psicológicas inatas inerentes à espécie. Decorre da própria natureza social do gênero humano, a partir do trabalho coletivo.

Leontiev (2004, p. 73), ao estudar a linha filogenética do desenvolvimento, afirma que o psiquismo humano adquiriu propriedades distintas em relação aos animais, pois no mundo animal as leis gerais que governam o desenvolvimento psíquico são as da evolução biológica, que envolvem funções elementares inatas, como a atenção involuntária. Essas funções elementares também estão presentes no homem, porém o trabalho coletivo provocado pela necessidade de sobrevivência, tanto acarretou uma evolução cultural quanto possibilitou transformações no próprio homem genérico.

À medida em que o gênero humano produzia instrumentos que contribuíam para sua sobrevivência, aprendia a manuseá-los e se transformava, isto é, apropriavase da cultura que produzia, acarretando uma mudança na relação do homem com o mundo, a qual gradativamente passava ser permeada pela função simbólica.

[...] tudo o que o indivíduo tem de humano é produto da apropriação das riquezas materiais e ideativas objetivadas ao longo da história da humanidade. [...] [Reciprocamente] [...] Por meio de sua atividade vital, o trabalho, o ser humano transforma a natureza impondo-lhe características humanas, ajusta a natureza aos seus objetivos e atribui aos objetos naturais significados e funções sociais 
(processo de objetivação), que serão apropriados por outros indivíduos (processo de apropriação). (ANJOS; DUARTE, 2017, p. 116-117).

Como Heller (1987) esclarece, a cultura humana é um produto desse trabalho coletivo do homem genérico, envolvendo não apenas a arte, a ciência e a técnica ao longo da história — genericidade "para si" —, como também os procedimentos cotidianos necessários à sobrevivência — genericidade "em si".

No cotidiano, o ser humano particular apropria-se da linguagem falada, dos usos e costumes, bem como dos instrumentos elementares utilizados em seu entorno e por ele. Essas produções cotidianas ou objetivações genéricas "em si”, ao longo da história, vem sendo diretamente apropriadas pelo indivíduo, em suas relações sociais, com o objetivo de satisfazer suas necessidades imediatas, passando a fazer parte desse indivíduo particular, ou seja, a individualidade "em si".

Entretanto, historicamente, o gênero humano foi complexificando a sua produção, ascendendo a instrumentos e técnicas mais afastadas do diretamente observável, superando a cotidianidade, constituindo as objetivações genéricas "para si”, relacionadas à ciência, à arte e à técnica. Dessa forma, o processo máximo de humanização do indivíduo consiste na apropriação dessa produção cultural genérica “para si” (HELLER, 1987; ANJOS; DUARTE, 2017).

Assim, para objetivar — transformar seu entorno com produtos de seus conhecimentos científicos, técnicos e artísticos - é necessário que o homem particular deles se aproprie, o que é possível, fundamentalmente, pelo trabalho coletivo. O trabalho, ao mesmo tempo em que produz a ciência, a arte e a técnica, é condição de sua apropriação, a qual resulta de um processo coletivo de mediação nas relações entre os homens, por meio da internalização dos signos, isto é, da linguagem, e pelo uso dos instrumentos. Nesse processo reproduzem-se os homens particulares, criando consequentemente a possibilidade da reprodução social (HELLER, 1987).

Dessa forma, “[...] o indivíduo, a criança, não é pura e simplesmente lançada no mundo dos homens, é aí introduzida pelos homens que a rodeiam e guiam este mundo" (LEONTIEV, 2004, p. 254). Destarte, o homem particular evolui na direção do homem genérico, do "em si" na direção do "para si". 
A constituição do sujeito na sua totalidade, respeitando as particularidades de cada aluno - portanto, daquele com indicativos de $\mathrm{AH} / \mathrm{SD}$ - parte do pressuposto do direito de todos a se humanizarem, isto é, a se desenvolverem do “ em si" na direção do "para si”, apropriando-se da cultura mais avançada produzida pela humanidade, uma vez que a individualidade "para si" promove a plena formação do indivíduo, permitindo-lhe "relacionar-se com a cotidianidade de forma consciente, mediada pelas objetivações genéricas "para si" (ANJOS, DUARTE, 2017, p. 118).

Para além da SRM, o enriquecimento curricular na sala de aula regular deve ser ofertado a todos os alunos, assim como é direito da pessoa com AH/SD. Propõe-se que a apropriação dos conteúdos escolares, com intencionalidade pedagógica definida, possibilite a cada indivíduo atingir o nível mais elevado de humanização "para si”, conforme preceitua a Teoria Histórico Cultural.

Pela apropriação dos conhecimentos científicos e pela interação social proporcionada pela vivência e troca com os colegas e o professor na sala de aula, a humanização mais elevada do sujeito "para si" expressa-se na sua forma de ser e estar no mundo, na sua forma de viver a vida, na empatia e na solidariedade que demonstra em seu cotidiano, nas relações com os outros seres humanos e com a natureza, ou seja, expressa-se também na genericidade "em si".

Compreender, na perspectiva da Teoria Histórico Cultural, como se desenvolve o psiquismo e as funções psicológicas superiores, possibilita ao professor, tanto da sala de aula regular quanto da SRM para AH/SD, a intencionalidade no processo pedagógico. A apropriação dos conceitos científicos permite ao aluno, atendido em sua singularidade, ascender e contribuir na evolução em direção ao ser humano genérico.

Com fundamento nesses pressupostos, retoma-se, a seguir, a legislação brasileira para $\mathrm{AH} / \mathrm{SD}$ e revisita-se esse conceito na própria legislação e na literatura. 


\section{A legislação brasileira para altas habilidades/superdotação}

Embora as pessoas com $\mathrm{AH} / \mathrm{SD}$ tenham sempre existido, as políticas públicas brasileiras começaram a considerá-las nos anos de 1970. A Lei 5.692/71 (BRASIL, 1971), em seu art. 9', utilizou pela primeira vez o termo "superdotado" determinando que deveriam receber tratamento especial, de acordo com normas fixadas pelos Conselhos de Educação.

Em 1994 o MEC (BRASIL, 1994) identificou a pessoa com AH/SD como público da Educação Especial, apresentando notável desempenho e elevadas potencialidades em qualquer dos seguintes aspectos isolados ou combinados: capacidade intelectual geral, aptidão acadêmica específica, pensamento criativo ou produtivo, capacidade de liderança, talento especial para artes e capacidade psicomotora.

A Lei de Diretrizes e Bases da Educação Nacional-LDB n ${ }^{0}$ 9.394/96, (BRASIL, 1996) definiu os superdotados como alunos com necessidades educacionais especiais, as quais seriam atendidas preferencialmente na rede regular para a modalidade Educação Especial, o que foi considerado um avanço em termos de conquista educacional.

Naquele momento ainda não se enfatizava o AEE. Em âmbito nacional, a Constituição Federal de 1988 em seu Art. 208, parágrafo VII, já previa a garantia de “[...] atendimento ao educando, em todas as etapas da educação básica, por meio de programas suplementares de material didático-escolar, transporte, alimentação e assistência à saúde" (BRASIL, 1988). Porém, ao assegurar a aceleração para os “superdotados", a LDB 9394/96 no Art. 59 formalizou-os como público da Educação Especial, possibilitando-lhes o benefício do AEE na forma da lei.

Destaca-se que historicamente esses avanços nas políticas públicas são frutos da luta política e ideológica dos grupos de representatividade da sociedade civil. Assim, "As políticas educacionais fazem parte da totalidade social [...] e a implementação de uma política pública é marcada por interesses econômicos, políticos e ideológicos” (GOMIDE, 2014, p. 131). 
No ano de 2008, com a colaboração de vários professores pesquisadores de universidades públicas, federais e estaduais, dentre estes alguns pesquisadores da área das Altas Habilidades, o Ministério da Educação-MEC através da Secretaria de Educação Especial produziu o documento Política Nacional de Educação Especial na Perspectiva da Educação Inclusiva (BRASIL, 2008) que anuncia, como objetivo, constituir políticas públicas promotoras de uma educação de qualidade para todos os alunos.

Este documento é um marco no caminho da constituição de uma escola pública como espaço de todos, ampliando a perspectiva do conceito de educação inclusiva. Reforça o entendimento de que a Educação Especial é uma modalidade que perpassa todos os níveis de ensino, devendo realizar o AEE, o qual, integrando a proposta pedagógica da escola, definiu como seu público os alunos com deficiência, transtornos globais de desenvolvimento e AH/SD (BRASIL, 2008).

Sobre o AEE o documento salienta que:

O atendimento educacional especializado identifica, elabora e organiza recursos pedagógicos e de acessibilidade que eliminem as barreiras para a plena participação dos alunos, considerando as suas necessidades específicas. As atividades desenvolvidas no atendimento educacional especializado diferenciam-se daquelas realizadas na sala de aula comum, não sendo substitutivas à escolarização. Esse atendimento complementa e/ou suplementa a formação dos alunos com vistas à autonomia e independência na escola e fora dela. $O$ atendimento educacional especializado disponibiliza programas de enriquecimento curricular, o ensino de linguagens e códigos específicos de comunicação e sinalização, ajudas técnicas e tecnologia assistiva, dentre outros. Ao longo de todo processo de escolarização, esse atendimento deve estar articulado com a proposta pedagógica do ensino comum (BRASIL, 2008).

O Decreto n. 7.611/11 (BRASIL, 2011) configura-se como um dos mais recentes documentos educacionais que determinam e asseguram o direito e ampliação da oferta do AEE, inclusive aos educandos com AH/SD.

Dentre os objetivos principais do AEE estão:

I - prover condições de acesso, participação e aprendizagem no ensino regular e garantir serviços de apoio especializados de acordo com as necessidades individuais dos estudantes; II - garantir a transversalidade das ações da educação especial no ensino regular; III - fomentar o desenvolvimento de recursos didáticos e pedagógicos que eliminem as barreiras no processo de ensino e aprendizagem; e 
IV - assegurar condições para a continuidade de estudos nos demais níveis, etapas e modalidades de ensino (BRASIL, 2011).

Os artigos $5^{\circ}$ e $7^{\circ}$ definem como o AEE para AH/SD será ofertado:

[...] prioritariamente, na sala de recursos multifuncionais da própria escola ou em outra escola de ensino regular, no turno inverso da escolarização, não sendo substitutivo às classes comuns [...].

Art. $7^{\circ}$ Os alunos com altas habilidades/superdotação terão suas atividades de enriquecimento curricular desenvolvidas no âmbito de escolas públicas de ensino regular em interface com os núcleos de atividades para altas habilidades/superdotação e com as instituições de ensino superior e institutos voltados ao desenvolvimento e promoção da pesquisa, das artes e dos esportes (BRASIL, 2011).

No Estado do Paraná, o órgão responsável pela implementação das políticas públicas para AH/SD é a Secretaria de Estado da Educação-SEED, através do Departamento de Educação Especial-DEEIN. Importantes documentos, emitidos pelo Conselho Estadual de Educação-CEE normatizam esse atendimento, como a Deliberação 09/2001, do (PARANÁ, 2001) que orienta a regulamentação das matrículas, bem como prevê a aceleração de estudos para alunos com AH/SD. E a Deliberação 02/03 (PARANÁ, 2003), que em seu Art. 06 lhes assegura ainda enriquecimento e aprofundamento curricular.

Esta aceleração denominada reclassificação deve ser consenso entre professores, equipe pedagógica e família. É um direito do estudante, consistindo no avanço dos estudos com o objetivo de cumprir o programa escolar em menor tempo, eliminar anos escolares e compactar o currículo sem prejuízos.

Já a Instrução no 016/08 (PARANÁ, 2008) e, posteriormente, a Instrução nº 010/2011(PARANÁ, 2011) estabelecem critérios para o funcionamento da SRM, na área de $\mathrm{AH} / \mathrm{SD}$ para a Educação Básica. Cabe aqui salientar que nem sempre funciona o AEE para AH/SD em todos os níveis de ensino, como se observa, por exemplo, nos anos iniciais do Ensino Fundamental, no município de Cascavel, caracterizando a invisibilidade da área (ALVES, 2017).

Como mais recente documento, a Deliberação 02/2016 do CEE dispõe sobre as normas para a modalidade Educação Especial no Sistema Estadual de Ensino do Paraná, e no capítulo IV discorre sobre o AEE, entendido como aquele 
de caráter complementar ou suplementar, ofertado para atender às necessidades educacionais dos estudantes, nas salas de recursos multifuncionais da própria escola ou em outra da rede regular de ensino, no turno inverso da escolarização, não sendo substitutivo às classes comuns (PARANÁ, 2016).

\section{O conceito de ah/sd nos documentos legais}

O documento do MEC intitulado "A Construção de Práticas Educacionais para Alunos com Altas Habilidades/ Superdotação” (BRASIL, 2007) conceitua os educandos com AH/SD como aqueles que apresentam grande facilidade de aprendizagem que os leva ao rápido domínio de conceitos, procedimentos e atitudes. Vale ressaltar a facilidade com que estes indivíduos se engajam em sua área de interesse, a qual é diversificada. Este entendimento "[...] permitiu que a Superdotação ultrapassasse a tradicional visão acadêmica para ser entendida em uma perspectiva mais plural" (BRASIL, 2007, p.28). Assim, nos documentos oficiais (BRASIL, 2008) encontra-se a seguinte descrição:

[...] Alunos com altas habilidades/superdotação demonstram potencial elevado em qualquer uma das seguintes áreas, isoladas ou combinadas: intelectual, acadêmica, liderança, psicomotricidade e artes. Também apresentam elevada criatividade, grande envolvimento na aprendizagem e na realização de tarefas em áreas de seu interesse (BRASIL, 2008, p. 15).

Diferentes autores, com diferentes concepções teóricas caracterizam AH/SD de forma semelhante, citando:

[...] precocidade, gosto e nível elevado de leitura; interesses variados e diferenciados; tendência a se associar com pessoas muito mais velhas (ou muito mais novas) em lugar de pessoas da mesma idade; assincronismo; preferência por trabalhar ou estudar sozinhos; independência; autonomia, senso de humor refinado; sensibilidade estética muito desenvolvida; elevada capacidade de observação; liderança e gosto e preferência por jogos que exijam estratégia, como o xadrez, dentre outras (PÉREZ, 2009, p. 303).

Para que a oferta do AEE ocorra, é necessário que o aluno seja identificado como pessoa com AH/SD. Por identificação entende-se o conjunto de instrumentos pedagógicos que podem ser utilizados para o reconhecimento de 
diferentes habilidades dos alunos em diversas áreas do conhecimento, considerando as especificidades das $\mathrm{AH} / \mathrm{SD}$.

Essa prática de identificação traz o contexto escolar e a observação docente como foco de análise, e permite verificar aspectos como diferentes estratégias que alguns alunos usam na resolução de problemas, seus interesses e motivações, bem como avaliar conhecimentos e estilos de aprendizagem, subsidiando o trabalho educacional (BRASIL, 2007).

Apesar de não haver consenso na literatura a respeito de estratégias a serem utilizadas na identificação das pessoas com indicativos de AH/SD, o MEC orienta que sejam aplicados instrumentos que não privilegiem somente o aspecto acadêmico do estudante, mas considerem igualmente os aspectos inerentes à capacidade de liderança, criatividade, além das competências psicomotoras e artísticas (BRASIL, 2007).

O objetivo da identificação deve ser mais incluir do que excluir. Não se trata de avaliar para colocar rótulos, nem privilegiar um grupo com tratamento de elite, como muitas ideias preconcebidas e injustificadas possam fazer crer, mas de atender às especificidades dos sujeitos (POCINHO, 2009). Evidencia-se a função primordial da educação escolar, possibilitando a apropriação das formas mais desenvolvidas do pensamento, na formação da individualidade dos alunos, possibilitando-lhes a apropriação das objetivações "para si” do gênero humano.

A importância do olhar atento do professor na identificação do potencial do aluno, não somente balizado pelos testes formais padronizados, é defendida pela Teoria Histórico Cultural quando aponta que, na sociedade capitalista com marcas tão profundas de expropriação e exclusão, os testes psicológicos têm contribuído para justificar diferenças como problemas individuais de ordem orgânica e contribuído para a exclusão dentro e fora do sistema escolar.

Definido quem é esse aluno, e a importância de identificá-lo, apresenta-se, na próxima seção, uma pesquisa de campo. Resgata-se a história do AEE ofertado ao aluno com AH/SD, no Núcleo Regional de Educação de Cascavel $^{1}$ e reflete-se

\footnotetext{
1 O NRE de Cascavel, cidade localizada no oeste paranaense, abrange mais de 90 escolas estaduais localizadas na cidade de Cascavel e demais cidades pertencentes a este Núcleo,
} 
sobre a materialização dessas políticas. A questão ora discutida é se essas políticas vêm cumprindo o papel de reconhecer que esse aluno, assim como os demais, tem o direito à máxima possibilidade de formação "para si”, de forma a, com seu potencial, vir a contribuir para a genericidade humana científica, artística ou técnica, conforme suas especificidades individuais.

\section{Metodologia}

A pesquisa de campo envolveu entrevistas individuais gravadas e transcritas com o diretor da primeira escola a ofertar a SRM para AH/SD no NRE de Cascavel - PR, as professoras que atuaram nesta primeira sala, o diretor ou diretora de cada SRM para $\mathrm{AH} / \mathrm{SD}$ em funcionamento atualmente, totalizando cinco diretores e seis professores. Também foram entregues, pessoalmente, questionários a 14 alunos e dez pais da SRM da cidade de Cascavel, dos quais retornaram às pesquisadoras sete devolvidos por alunos e dez por pais.

Analisa-se a situação de um Núcleo Regional de Educação, entendendo que, sendo parte do sistema estadual de educação, apresenta peculiaridades semelhantes, “em um nível mais abstrato" (HELLER, 1987, p. 20), às demais regiões do estado, ressalvadas as discrepâncias decorrentes da localização do NAAH/S, como se constatou na pesquisa.

A partir dos objetivos, os dados coletados foram tratados com base na Análise de Conteúdo (BARDIN, 2011) estabelecendo-se três categorias: os recursos materiais, didático-pedagógicos e o processo pedagógico na SRM para AH/SD; a formação específica para atuação na SRM para AH/SD; desafios, dificuldades e avanços do AEE para AH/SD na visão dos diretores, professores, pais e alunos. Ainda, com fundamento na Teoria Histórico-Cultural buscou-se analisar essas categorias, tomando por base os princípios da contradição, da totalidade e da mediação que norteiam esse referencial.

Para preservar a identidade dos participantes, seus nomes originais foram substituídos pela especificação de suas funções: Professora (P), Diretora/Diretor (D), Aluno (A), seguidos de um número sequencial.

totalizando 18 municípios. Atende por volta de 40.000 alunos, distribuídos nas 90 escolas estaduais, ofertando a educação básica do Ensino Fundamental anos finais e Ensino Médio, bem como a Educação Profissionalizante e Educação de Jovens e Adultos. 


\section{Análise e discussão dos resultados}

Com relação ao NRE de Cascavel, a primeira SRM especificamente para AH/SD iniciou seu trabalho no ano de 2011, localizada na escola Julia Wanderley, na cidade de Cascavel.

Regulamentou-se pela Instrução n 010/2011-SUED/SEED, a qual a especifica como “[...] um espaço organizado com materiais didático-pedagógicos, equipamentos e profissional (is) especializado(s) onde é ofertado o atendimento educacional especializado que visa atender às necessidades educacionais dos alunos público alvo da Educação Especial na Rede Pública de Ensino” (PARANÁ, 2011). Essa sala encerrou suas atividades no ano de 2015.

Entre os principais fatores que contribuíram para seu fechamento, o diretor cita a questão estrutural, relativa à falta de profissionais habilitados e à falta de materiais específicos para o desenvolvimento do trabalho, e complementa:

Também têm uns que tiveram dificuldade no transporte, eles tinham que pagar o vale transporte, pelo menos a metade, mas a gente ia contornando, ajudava de um lado, de outro, dependia também da família, do incentivo (D1).

No ano de 2013 foi autorizada mais uma SRM na cidade de Corbélia, e em 2014, outra sala na cidade de Cascavel. Até o ano de 2019, o NRE de Cascavel apresentava as seguintes SRM para AH/SD: 
Tabela 1 - Número de alunos matriculados na SRM para AH/SD nos últimos anos no NRE de Cascavel

\begin{tabular}{|l|c|c|c|c|c|}
\hline ANO & $\begin{array}{c}\text { Colégio } \\
\text { Estadual Júlia } \\
\text { Wanderley- } \\
\text { Cascavel-PR }\end{array}$ & $\begin{array}{c}\text { Colégio } \\
\text { Estadual } \\
\text { Padre } \\
\text { Carmelo } \\
\text { Perrone- } \\
\text { Cascavel-PR }\end{array}$ & $\begin{array}{c}\text { Colégio } \\
\text { Estadual } \\
\text { Duque de } \\
\text { Caxias- } \\
\text { Corbélia PR }\end{array}$ & $\begin{array}{c}\text { Colégio } \\
\text { Estadual } \\
\text { Olavo } \\
\text { Bilac- } \\
\text { Corbélia- } \\
\text { PR }\end{array}$ & $\begin{array}{c}\text { Colégio } \\
\text { Estadual } \\
\text { Monteiro } \\
\text { Lobato-Céu } \\
\text { Azul-PR }\end{array}$ \\
\hline $\mathbf{2 0 1 2}$ & 6 & - & - & - & - \\
\hline $\mathbf{2 0 1 3}$ & 14 & - & 10 & - & - \\
\hline $\mathbf{2 0 1 4}$ & 4 & 6 & 10 & - & - \\
\hline $\mathbf{2 0 1 5}$ & 9 & 11 & 9 & - & - \\
\hline $\mathbf{2 0 1 6}$ & - & 10 & 8 & - & 1 \\
\hline $\mathbf{2 0 1 7}$ & - & 6 & 11 & 1 & 2 \\
\hline $\mathbf{2 0 1 8}$ & - & 11 & 12 & 1 & 4 \\
\hline $\mathbf{2 0 1 9}$ & - & 25 & 17 & 4 & - \\
\hline
\end{tabular}

Fonte: Dados fornecidos pelo Sistema SERE.

Observa-se que o pequeno número de alunos que vem frequentando o AEE para AH/SD no NRE de Cascavel, nos últimos anos tem aumentado. A SRM de Cascavel registrava em 2019, 25 alunos, sendo 16 avaliados e 9 em processo de avaliação, porém já em atendimento. Entretanto, ainda 30 alunos aguardavam o início das avaliações para possível frequência. Estes alunos já poderiam estar na SRM, o que demandaria investimento humano e material. Porém a lei, apesar de prever, na materialidade das ações, não garante.

Para o ano de 2020, mais duas SRM para AH/SD estavam autorizadas, uma em Corbélia no Colégio Estadual Amâncio Moro e outra em Ibema, no Colégio Estadual José de Anchieta, porém interrompeu-se o trabalho devido à pandemia da Covid-19.

Supõe-se que o aumento no número de SRM para AH/SD observado nos números oficiais informados seja consequência da aproximação entre a Educação Superior e a Educação Básica, por meio dos cursos e pesquisas desenvolvidos pelo Grupo de Pesquisa Aprendizagem e Ação Docente-GPAAD, em colaboração com o Programa de Educação Especial-PEE, que envolvem docentes e discentes da 
Universidade Estadual do Oeste do Paraná — Unioeste, e a equipe pedagógica do NRE Cascavel, que atua no $\mathrm{CRAPE}^{2}$, comprovando a importância e necessidade dessa aproximação. No entanto, faz-se necessário ampliar este trabalho.

O Paraná possui atualmente 1.853 alunos matriculados em SRM para $\mathrm{AH} / \mathrm{SD}$, conforme a Tabela 2.

Tabela 2 - Número de alunos atendidos em SRM para AH/SD no PR em 2019, por mesorregião geográfica

\begin{tabular}{|c|c|}
\hline REGIÃO & NÚMERO DE ALUNOS \\
\hline Noroeste & 23 \\
\hline Centro Ocidental & 43 \\
\hline Norte Central & 699 \\
\hline Norte Pioneiro & 69 \\
\hline Centro Oriental & 27 \\
\hline Sudoeste & 140 \\
\hline Oeste & 196 \\
\hline Centro Sul & 111 \\
\hline Sudeste & 101 \\
\hline Reg. Metropol. Curitiba & 444 \\
\hline TOTAL & $\mathbf{1 8 5 3}$ \\
\hline
\end{tabular}

Fonte: Dados fornecidos pela SEED/PR.

O maior número de alunos atendidos nas SRM para AH/SD localiza-se geograficamente no norte central do Paraná, onde se encontra o Núcleo de

2 O Centro Regional de Apoio Pedagógico Especializado - CRAPE - objetiva prestar apoio pedagógico especializado às escolas, educadores e alunos com deficiência/necessidades especiais dos municípios de abrangência do NRE de Cascavel na perspectiva da educação inclusiva. A avaliação psicológica dos alunos da Educação Especial, quando necessária, é prestada por este serviço. 
Atividades de Altas Habilidades/Superdotação-NAAH/S 3 paranaense, demonstrando a importância desse núcleo para a área, até mesmo pelo número de alunos atendidos. No entanto, questiona-se os limites de sua área de abrangência.

$\mathrm{O} \mathrm{NAAH} / \mathrm{S}$ paranaense já deveria ter sido ampliado, pois na ocasião de sua criação, o intuito era aumentar o número de alunos identificados (PARANÁ, 2010). Para isso, a formação continuada para professores, também função desse núcleo, é essencial. No entanto, não dispõe de profissionais e recursos físicos e financeiros para desenvolver seu trabalho junto às demais regiões do Estado, no sentido de incentivar o aumento de alunos identificados e instrumentalizar teoricamente as Salas de Recursos existentes.

Até fevereiro de 2013, o Estado do Paraná possuía 54 SRM para AH/SD e atendia um público de 593 alunos (LYRA, 2013). Atualmente, segundo dados fornecidos pela SEED-PR, em maio de 2019, 85 turmas atendiam 1.853 alunos, portanto em seis anos houve um aumento de $57 \%$ no número de salas e $212 \%$ no número de alunos atendidos.

Porém, ainda que se observe um aumento gradativo, o número de salas de atendimentos é bem distante do que deveria, do ponto de vista teórico e prático. Os números atuais de atendimento no Estado do Paraná revelam que, em cada um dos 31 NREs no Estado, há a oferta de pelo menos uma Sala de Recursos para AH/SD em funcionamento.

No que diz respeito à legislação que estabelece os critérios e assegura o direito de atendimento a pessoas com indicativos de $\mathrm{AH} / \mathrm{SD}$, o Brasil bem como o Paraná estão à frente até mesmo de outros países (MATTOS; MACIEL, 2016).

\footnotetext{
${ }^{3}$ No ano de 2005, foram implantados pelo MEC em colaboração com as Secretarias Estaduais da Educação, os NAAH/S, em todas as capitais estaduais brasileiras e no Distrito Federal, à exceção do Estado do Paraná e do Estado do Rio de Janeiro, onde o núcleo se localiza no interior, respectivamente nas cidades de Londrina e Niterói. Localizado na cidade de Londrina-PR, nas dependências do Colégio Estadual Vicente Rijo, o NAAH/S paranaense está em funcionamento desde o ano de 2006, porém sua oficialização ocorreu em 2010 (RIBEIRO, 2017).
} 
Assim, o que se constata é que entre a letra da lei e a efetividade das políticas públicas ainda existe um abismo. Para refletir sobre os aspectos que envolvem estes fatores, elencaram-se algumas categorias de análise, apresentadas a seguir.

\subsection{Quanto aos recursos materiais, didático-pedagógicos e o processo pedagógico na SRM para AH/SD}

A Instrução 010/2011-SUED/SEED (PARANÁ, 2011) seguindo os documentos oficiais nacionais diz que a SRM para AH/SD deverá ser organizada com materiais didáticos de acessibilidade, equipamentos tecnológicos e mobiliários que compõem um kit disponibilizado pelo MEC, bem como outros recursos pedagógicos específicos e adaptados, disponibilizados para a escola pela mantenedora.

No entanto, os recursos nem sempre chegam às unidades escolares ou são suficientes. Em entrevista, 75\% dos diretores das SRM para AH/SD atualmente ofertadas no NRE de Cascavel, quando questionados sobre a escola ter recebido materiais, equipamentos ou tecnologia afirmaram que não houve qualquer repasse deste tipo de insumo específico. Como reitera D3: “apesar de insistentes solicitações à SEED [...]".

Uma das professoras, que trabalha há mais tempo com $\mathrm{AH} / \mathrm{SD}$, informa que a escola recebeu na implantação da SRM um kit de equipamentos, porém os outros materiais têm sido adquiridos com seus recursos ou da própria escola.

Ainda, a Instrução 010/2011-SUED/SEED estabelece critérios para a SRM para $\mathrm{AH} / \mathrm{SD}$, prevendo no artigo 6.2 que:

A ação pedagógica deverá constituir um conjunto de procedimentos específicos, que tem por objetivo enriquecer a aprendizagem, oportunizando intervenção nas áreas das habilidades e interesses dos alunos, com parcerias estabelecidas pela escola e outras instituições/organizações afins. Oportunizará o desenvolvimento nos relacionamentos intra e interpessoais, priorizando o autoconhecimento e a socialização das pesquisas (PARANÁ, 2011).

Portanto, como também pontuam as professoras que trabalham com $\mathrm{AH} / \mathrm{SD}$, ao aluno devem ser oportunizadas diversas opções de enriquecimento da 
aprendizagem, além de recursos pedagógicos diversificados, com o objetivo de desenvolver e potencializar suas capacidades.

O Quadro 1, a seguir, apresenta a atual distribuição e fonte desses recursos, de acordo com o relato dos professores que atuam nas SRM para AH/SD.

Quadro 1 - Distribuição e Fonte dos Recursos didáticos pedagógicos conforme relato docente

\begin{tabular}{|l|l|}
\hline Categoria & Resposta \\
\hline Próprio professor & Os recursos são limitados. Muitas vezes levei material meu para o \\
trabalho com os alunos. A SRM deve receber uma atenção \\
orçamentária maior (P2); \\
Busco recursos diversos até porque há áreas de interesse distintas \\
entre os alunos. De uma forma geral utilizo ferramentas digitais, \\
filmes, livros, jogos de tabuleiro, sucatas e recursos externos \\
quando possível (P5); \\
Geralmente é um trabalho solitário, não tem muitas opções de \\
recursos. Procuro sugestões na internet e com colegas (P1); \\
Sempre que necessito de algo a mais, solicito à direção, e quando \\
não recebo, eu mesma compro. Tenho um acervo de materiais \\
adquiridos para este trabalho, pois acredito que minha atuação \\
como professora nessa área vai além da vida profissional, é \\
também, no meu caso, uma realização pessoal e social (P4).
\end{tabular}

Fonte: Dados colhidos por Vieira (2019).

A comparação entre os recursos fornecidos pelo Estado (33\%) e os recursos adquiridos por parcerias com outras instituições ou pelo próprio professor $(67 \%)$ 
revela o quanto o Estado tem se omitido no sentido de prover os recursos pedagógicos para a consecução do trabalho docente.

Questionados sobre as atividades que realizam na sala de recursos, o grupo de alunos entrevistados citou:

Aqui na sala de recursos temos jogos que estimulam nossa criatividade e nosso raciocínio, também temos a oportunidade de desenvolver projetos e a professora nos leva a eventos muito interessantes ( $A 1$ ); gosto dos jogos de RPG e dos projetos de arte ( A2); aqui na sala de AH/SD temos bastante autonomia para nos expressar, desenvolver atividades diferentes e podemos realizar as atividades da sala de aula que temos dificuldade contando com os colegas do grupo ( A3).

Os alunos demonstram interesse pelas atividades da SRM pois lhes proporcionam um aprendizado além daquele ofertado em sala de aula regular. As atividades coletivas realizadas pela SRM com os alunos participantes também colaboram para que se socializem, como se observa no excerto de um pai:

As atividades coletivas são muito motivadoras, pois eles fazem amizades e conversam sobre assuntos que têm interesses além da escola, sem a preocupação de preconceitos e julgamentos, pois todos têm algo em comum: não se socializam fácil com outras pessoas, são exigentes no vocabulário, duvidam das teorias existentes, criticam de forma sincera o que não acreditam, são sensíveis emocionalmente e demonstram humor sarcástico (P4).

Nesse viés, na medida em que o adolescente se apropria dos conhecimentos clássicos que envolvem arte, filosofia, ciência e tecnologia, pode conduzir a vida cotidiana a um fim específico na direção da genericidade, de forma consciente (ANJOS; DUARTE, 2017). As atividades desenvolvidas na SRM colaboram para este processo, porém, há que se proporcionar as condições materiais específicas necessárias.

Nas falas dos diretores escolares entrevistados, denota-se ciência de que a SRM para AH/SD necessita de investimentos, de material diversificado, acesso à tecnologia e atendimento a demandas específicas. A iniciativa de professores que trabalham na área, adquirindo materiais com recursos próprios é honrosa, demonstra o comprometimento profissional. No entanto, a responsabilidade pela manutenção das escolas é da mantenedora. O fato de os recursos não chegarem até as SRM, demonstra que as políticas públicas não estão atingindo seu objetivo. 
Todos os diretores entrevistados alegam que, na medida do possível, a escola procura atender às necessidades básicas de materiais solicitados pelas professoras atuantes na SRM para AH/SD, com os recursos da própria escola e recursos recebidos através do Programa Dinheiro Direto na Escola-PDDE. Porém, ressaltam que as Salas carecem de recursos e investimentos específicos.

\subsection{Quanto à Formação Específica para Atuação na SRM para AH/SD}

A escolha do profissional para atuar na Educação Especial, no Estado do Paraná, segue instrução própria. No caso da SRM para AH/SD não há fixação de profissionais nas escolas, a cada fim de ano letivo as aulas são redistribuídas e pode ocorrer a substituição de professores. A experiência profissional com a SRM para $\mathrm{AH} / \mathrm{SD}$ deveria ser levada em consideração para o suprimento das vagas, porém não é isso que ocorre.

Como requisito para a abertura da sala, consta na instrução que é necessário o professor especializado em Educação Especial, preferencialmente com a comprovação de estudos na área de AH/SD. Note-se que a formação específica para a área não é obrigatória. Também na distribuição de aulas exige-se o curso de especialização em Educação Especial, sem especificar a área de formação.

A seleção do profissional para atuar nas SRM para AH/SD é citada pelos diretores como mais um dos desafios enfrentados para a ampliação da oferta do AEE, como verificado nos excertos abaixo:

Contamos com a sorte na contratação do professor. Não existe critério específico para a contratação. Aqui na minha cidade acaba sendo encaminhado professor PSS. Portanto, cada ano é um professor diferente (D3).

A escolha do profissional é realizada por meio de contratação via NRE e geralmente não há a continuidade do trabalho devido os professores da Sala de Recursos não estarem fixados nos estabelecimentos de ensino. Agora demos muita sorte de estar com uma professora há um tempo, muito competente, que se dedica, mas nem sempre isso é possível (D4).

Não existe amparo legal, em nível federal, estabelecendo critérios que autorizem os professores com formação ou experiência anterior na área de AH/SD a terem prioridade para assumirem as turmas das SRM. As resoluções estaduais 
poderiam oferecer a manutenção da equipe de professores para a continuidade do trabalho, pois essa rotatividade é um empecilho ao trabalho pedagógico, conforme citam os diretores.

Pérez e Freitas (2011) defendem a necessidade de incluir conhecimentos específicos sobre a área das $\mathrm{AH} / \mathrm{SD}$ em cursos de formação, tanto inicial quanto continuada. Nas licenciaturas nem existe formação específica na Educação Especial, quanto mais na área das AH/SD. Além disso, os cursos de pós-graduação pouco ou nada contemplam sobre essa área, somente abordam as outras que compõem a Educação Especial.

A falta de formação específica sobre a temática nos cursos de Pedagogia, nas licenciaturas e especializações, colabora com a invisibilidade dos alunos com indicativos de AH/SD. Verifica-se, ainda, que a formação continuada que deveria ser ofertada pelo Estado é igualmente falha, obrigando o profissional a buscá-la por conta própria:

\begin{abstract}
Após conhecer e me aprofundar nessa temática, me tornei uma pesquisadora nessa área e procurei formações específicas, como não houve nenhum curso por parte da SEED (de 2014 a 2017), pelo menos não fui convidada, busquei os eventos nacionais e internacionais para me atualizar e formar nessa área, todos com recursos próprios. O único curso que participei com auxílio da SEED, foi em 2018, na $1^{\text {a }}$ Conferência de Aprendizagem Criativa em Curitiba, esse evento foi muito importante para o meu planejamento das atividades de enriquecimento curricular; em 2019 somente tive formação por minha conta também (P4)
\end{abstract}

Constata-se que o profissional que atua na SRM para AH/SD acaba por buscar formação por iniciativa e recursos próprios, mesmo não tendo a garantia de permanência na SRM. Embora 60\% dos professores ao assumirem a SRM para $\mathrm{AH} / \mathrm{SD}$ tivesse já concluído o curso de extensão sobre a temática, $40 \%$ dos professores entrevistados respondeu que iniciou o trabalho sem conhecer nada sobre a área, e sua especialização para Educação Especial não contemplou AH/SD.

Os diretores e professores entrevistados são unânimes em indicar a necessidade de incluir o tema das AH/SD nos cursos de formação inicial das licenciaturas, inclusive na especialização em Educação Especial. Registre-se que a Portaria n. ${ }^{\circ}$ 1.793, de dezembro de 1994 (BRASIL, 1994) recomenda a inclusão da disciplina “[...] Aspectos ético-político educacionais da normalização e integração da 
pessoa portadora de necessidades especiais", prioritariamente nos cursos de Pedagogia, Psicologia e em todas as Licenciaturas. No entanto, na prática a realidade é outra.

Também se faz necessária a discussão do assunto em cursos de formação continuada para todos os professores que atuam com a Educação Básica, pois desenvolvem o trabalho no dia a dia e o conhecimento na área pode contribuir para um atendimento mais apropriado e humano a todos os alunos, não somente aos alunos identificados e em processo de avaliação e atendimento.

\subsection{Desafios, dificuldades e avanços do AEE para AH/SD na visão dos diretores, professores, pais e alunos}

Constatou-se que o principal desafio citado pelos diretores com relação à SRM para AH/SD é a falta de profissionais com perfil adequado para o trabalho de atendimento aos alunos no AEE, seguido de escassez de materiais para o desenvolvimento do trabalho, o que revela lacunas na formação docente inicial e continuada, bem como falta de investimento público que garanta as condições de trabalho dos profissionais que atuam na área.

Os professores concordam que a falta de recursos financeiros e materiais para o trabalho específico, a burocracia e falta de tempo para o trabalho propriamente pedagógico, são seus maiores desafios. Destacam, também, as dificuldades enfrentadas pelo aluno como sujeito com AH/SD.

Apesar das dificuldades, os gestores e professores relatam ter ciência da contribuição do trabalho desenvolvido em suas escolas, tanto para os alunos quanto para a área das AH/SD no NRE de Cascavel, conforme Quadro 2. 
Quadro 2 - Contribuição e avanços da SRM para AH/SD na visão de diretores, professores e alunos

\begin{tabular}{|l|l|}
\hline Categoria & Respostas \\
\hline \multirow{5}{*}{ Diretores } & $\begin{array}{l}\text { [...] oportunidade de ter um atendimento pedagógico diferenciado de acordo } \\
\text { com suas habilidades, o que não é possível na sala de aula regular; [...] } \\
\text { suplementação curricular e complementação; [...] os alunos se descobrem em } \\
\text { relação à sua habilidade, desenvolvem a autoestima, pois muitos não se } \\
\text { consideram capazes, apresentam problemas com ansiedade, não conseguem } \\
\text { se compreender no "mundo"; trabalhar com o emocional, interação social } \\
\text { (outro fator que na maioria das vezes é um entrave para eles) nosso trabalho } \\
\text { já fez e faz a diferença para muitos. } \\
\text { [...] a SRM para o aluno com AH/SD deve representar um espaço que } \\
\text { oportunize liberdade para aprender, enriquecimento de aprendizagens, trocas } \\
\text { de experiências e vivências entre seus pares; [...] a área ainda requer } \\
\text { visibilidade e fortalecimento; Os alunos demonstram gostar muito de } \\
\text { participar, faltam quando têm outras atividades fora da escola, como terapias, } \\
\text { cursos específicos de Línguas Estrangeiras e Informática; [...] Possibilitar a } \\
\text { participação de todos nas atividades extracurriculares nas áreas de seus } \\
\text { interesses para que possam socializar seus conhecimentos e experiências } \\
\text { prévias e tácitas, desenvolver habilidades e produzir outros conhecimentos, } \\
\text { que valorizem seus talentos numa perspectiva social, respeitando suas } \\
\text { características inter e intrapsíquicas. Além disso, quero que sejam felizes como } \\
\text { pessoas únicas, que aprendam a se defender dos conflitos humanos de forma } \\
\text { crítica, criativa e autônoma. }\end{array}$ \\
$\begin{array}{l}\text { [...] desenvolve o aprendizado com assuntos que não são abordados na sala } \\
\text { de aula regular; [...] a interação, comunicação e relacionamento com as } \\
\text { pessoas melhorou consideravelmente; mais segurança e criatividade e melhor } \\
\text { convivência com os pares. }\end{array}$ \\
\hline Alunos
\end{tabular}

Fonte: Dados colhidos por Vieira (2019).

Os depoimentos de diretores, professores, pais e alunos demonstram a importância do AEE na SRM para AH/SD no NRE de Cascavel, e apontam os desafios que a área enfrenta desde sua implantação. Há necessidade de se produzir demanda por meio da identificação dos alunos que estão na invisibilidade. Porém, a pressão da sociedade civil é crucial para que as políticas públicas, que até existem e se configuram como um campo não harmônico de disputas, possam ser realmente implementadas.

Os sujeitos com $\mathrm{AH} / \mathrm{SD}$ existem e devem ser considerados. Como público da Educação Especial, precisam de encaminhamento específico, de forma a atender suas necessidades educacionais. 


\section{Considerações finais}

Conforme Ribeiro (2017), as políticas a nível federal não se desenvolvem com igualdade e simultaneamente em todas as regiões, há uma disparidade muito grande entre os estados que vão delineando as questões específicas, de acordo com resoluções próprias. Também as políticas estaduais e municipais no AEE para $\mathrm{AH} / \mathrm{SD}$, são aplicadas ou não, de formas diferentes.

A área das AH/SD compõe a modalidade da Educação Especial, a qual deve perpassar todos os níveis e modalidade de ensino e está prevista em leis e resoluções, porém é a mais negligenciada por falta de visibilidade e conhecimento teórico.

Historicamente, as políticas públicas dentro da Educação Especial decorrem de luta social e histórica travada pela sociedade civil, e, quando se trata de AH/SD a invisibilidade da área estende-se aos sujeitos que dela fazem parte. Entretanto, é preciso pensar em políticas públicas que possibilitem incluí-lo, uma vez que ele também é um sujeito de direitos, o que significa que não se pode perdê-lo de vista.

Não basta dizer que o que está nas leis precisa ser cumprido. É necessário definir estratégias e possibilidades para que o atendimento se efetive dentro do contexto de condições de trabalho e formação dos professores. A legislação prevê o direito, porém a aplicação deste direito será garantido na prática educacional.

A sociedade civil alheia à descontinuidade das políticas deve ser chamada à responsabilidade: a formação precária convoca as Universidades que precisam rever seus currículos nas licenciaturas quanto à formação integral dentro da Educação Especial inclusiva. Faz-se urgente, também, que o trabalho conjunto desenvolvido entre a Educação Superior e a Educação Básica seja ampliado, e que a Universidade ocupe seu papel no desenvolvimento de pesquisa e extensão junto à comunidade, também na área de $\mathrm{AH} / \mathrm{SD}$, entendendo que a escola tem o compromisso de possibilitar a todos seus alunos o máximo desenvolvimento.

As Secretarias de Educação municipal e estadual devem ser responsabilizadas quanto à formação continuada e quanto à garantia de condições de trabalho aos professores do ensino regular e da Educação Especial. Nesse sentido, há a 
necessidade de sindicatos fortes, por meio dos quais os professores busquem a garantia dos seus direitos.

A análise dos dados destacou a importância da SRM para alunos com indicativos de $\mathrm{AH} / \mathrm{SD}$. Porém também denunciou a carência de recursos financeiros e estruturais - estrutura física/material, didática/pedagógica, equipamentos/recursos tecnológicos —, carências na formação docente inicial e continuada, além da identificação tardia dos indicativos de AH/SD.

Os pontos importantes que emergem a partir deste estudo revelam o necessário desafio da área e de todos os envolvidos com a educação, ou seja, o compromisso não somente com a formulação das políticas, mas, também em suas implementações, gestão e avaliação.

Outro aspecto importante refere-se à identificação dos alunos com AH/SD o mais cedo possível, já nos anos iniciais do Ensino Fundamental, pois sem identificá-los não ocorre o AEE. A identificação também contribui para mobilizar as políticas públicas.

Assim, há a urgência da defesa de uma Política Nacional de Educação Especial na perspectiva da Educação Inclusiva, com garantia de formação inicial e continuada para professores de forma consistente e com fundamentação teórica apropriada, que entenda e trate o sujeito como um todo e não de forma fragmentada, pois se não tiver formação inicial e continuada que oferte disciplinas e conceitue todas as áreas da Educação Especial, não se cumpre a lei.

Nenhuma legislação por si só surtirá resultado se não houver trabalho e ações de engajamento coletivas que façam com que as leis se cumpram. A participação efetiva da sociedade civil é primordial. O Estado não consegue cumprir as leis a que se propõe e esse duelo de direitos não pode perpetuar-se dentro da escola. E o mais essencial: o aluno e seu desenvolvimento humano pleno não pode ficar à mercê dessas disputas.

Entretanto, há que se ter clareza no sentido de que todos os que chegam à escola têm o direito de se apropriarem dos conhecimentos clássicos produzidos historicamente pela humanidade, pois a Educação Básica deve ser inclusiva e ter como objetivo a humanização de todos os sujeitos que acolhe. 
Isso significa alçar o aluno, da individualidade "em si" — a qual vem se desenvolvendo desde seu nascimento, envolvendo a apropriação dos usos e costumes cotidianos de seu grupo social —, à individualidade "para si" — sua máxima possibilidade de desenvolvimento, possibilitando-lhe uma participação social analítica e consciente.

$\mathrm{Na}$ relação dialética entre a individualidade "em si” e a individualidade "para si”, à medida em que se apropria dos conhecimentos sistematizados, a individualidade "para si" vai possibilitando ao aluno autorregular seu comportamento, aproximando-se do gênero humano pela apropriação de suas produções culturais.

Daí a importância de elaboração e garantia de implementação de políticas públicas que possibilitem à escola contribuir nesse processo. Esse é o grande desafio da escola, possibilitar a cada aluno, quaisquer que sejam suas condições individuais e sociais, a apropriação das objetivações humanas necessárias ao seu desenvolvimento omnilateral.

Há um projeto societário e de educação em disputa na atualidade, intimamente vinculado ao atual momento histórico, que se traduz na privatização como política pública. A defesa da Educação Especial não é suficiente, é preciso defender e problematizar o projeto de sociedade que interessa à classe trabalhadora.

Nesse projeto, pela apropriação dos conhecimentos científicos, artísticos e técnicos, produzidos por toda a humanidade, os indivíduos particulares estarão melhor preparados para a leitura e consequente atuação na prática social, de forma a extrapolar o senso comum e socialmente agregar-se, pelo trabalho coletivo, ao gênero humano, à genericidade "para si".

\section{Referências}

ALVES, V. S. Altas Habilidades/Superdotação na Rede Pública Municipal de Cascavel: uma análise na perspectiva da psicologia histórico-cultural. 2017. 169 f. Orientador: Maria Lídia Sica Szymanski Dissertação (Mestrado em Educação) - Universidade Estadual do Oeste do Paraná, Cascavel, 2017.

ANJOS, R.E.; DUARTE, N. A teoria da individualidade para si como referência à análise da educação escolar de adolescentes. Nuances: estudos sobre Educação, Presidente Prudente-SP, v. 28, n. 3, p. 115-132, set./dez. 2017.

BARDIN, L. Análise de conteúdo. São Paulo: Edições 70, 2011. 
BRASIL. Ministério da Educação. Lei no 5.692, de 11 de agosto de 1971. Lei de diretrizes e bases para o ensino de $1^{\circ}$ e $2^{\circ}$ graus. Brasília, DF: MEC, 1971. Disponível em: http://www.planalto.gov.br/ccivil_03/leis/15692.htm acesso em: 25 set. 2020.

BRASIL. Constituição 1988. Constituição da República Federativa do Brasil de 1988. Brasília, DF: Presidência da República. Disponível em: http://www.planalto.gov.br/ccivil_03/Constituicao/Constituiçao.htm. Acesso em: 4 out. 2020.

BRASIL. Ministério da Educação e do Desporto. Secretaria de Educação à Distância. Política nacional de educação especial. Brasília, DF: MEC/SEESP, 1994.

BRASIL. Ministério da Educação. Lei no 9.394, de 20 de dezembro de 1996. Lei de Diretrizes e Bases da Educação Nacional. Brasília, DF: MEC, 1996. Disponível em: http://www.planalto.gov.br/ccivil_03/leis/19394.htm. Acesso em: 20 out. 2020.

BRASIL. A Construção de Práticas Educacionais para Alunos com Altas Habilidades/Superdotação. Secretaria de Educação Especial. Disponível em: http://portal.mec.gov.br/seesp/arquivos/pdf/altashab4.pdf. Acesso em: 11 out. 2020.

BRASIL. Política Nacional de Educação Especial na Perspectiva da Educação Inclusiva. Brasília: MEC/SEESP, 2008.2 Disponível em: http:/ / portal.mec.gov.br/index.php?option $=$ com_content\&view $=$ article\&id $=12907$ :legisla coes\&catid=70:legislacoes. Acesso em: 10 set. 2020.

BRASIL. Ministério da Educação. Decreto $n^{0}$ 7.611, de 17 de novembro de 2011. Dispõe sobre a educação especial, o atendimento educacional especializado e dá outras providências. Brasília, DF: MEC, 2011. Disponível em: http://www.planalto.gov.br acesso em: 10. ago 2020.

GOMIDE, D.C. O Materialismo Histórico-Dialético como enfoque metodológico para a pesquisa sobre Políticas Educacionais. In: XII JORNADA DO HISTEDBR E X SEMINÁRIO DE DEZEMBRO. Anais... 12. ed. 2014. Disponível em: http://www.histedbr.fe.unicamp.br/, acesso em: 07 jul. 2020.

HELLER, A. Sociología de la vida cotidiana. Trad. J. F. Yvars e. Pérez Nadal. Barcelona: Península, 1977.

LEONTIEV, A. O Desenvolvimento do Psiquismo. Trad. Rubens Eduardo Frias. 2 ed. São Paulo: Centauro, 2004.

LYRA, J. C. Atendimento Educacional Especializado de alunos com Altas Habilidade/Superdotação na cidade de Londrina, Paraná: um estudo de caso. 145 f. Orientador: Maria Cristina Marquezine Mestrado em Educação (Mestrado em Educação) 2013, 149 p.- Universidade Estadual de Londrina, Londrina, 2013.

MATOS, B. C; MACIEL, K. C. Políticas Educacionais do Brasil e Estados Unidos para o Atendimento de Alunos com Altas Habilidades/Superdotação (AH/SD). Revista Brasileira Ed. Esp., Marília, v. 22, n. 2, abr.-jun. 2016. 
PARANÁ. Câmara de Legislação e Normas. Deliberação n. ${ }^{\circ}$ 09/01 de 01 de Outubro de 2001. Matrícula de ingresso, por transferência e em regime de progressão parcial; o aproveitamento de estudos; a classificação e a reclassificação; as adaptações; a revalidação e equivalência de estudos feitos no exterior e regularização de vida escolar em estabelecimentos que ofertem Ensino Fundamental e Médio nas suas diferentes modalidades. Curitiba, 2001. Disponível em: http://diaadiaeducacao.pr.gov.br. Acesso em: 09 maio 2020.

PARANÁ. Comissão Temporária de Educação Especial. Deliberação no 2/03 de 02 de junho de 2003. Institui Normas para a Educação Especial, modalidade da Educação Básica para alunos com necessidades educacionais, no Sistema de Ensino do Estado do Paraná. Curitiba, 2003. Disponível em http://diaadiaeducacao.pr.gov.br. Acesso em 08 mai. 2020.

PARANÁ. Secretaria de Estado da Educação Superintendência da Educação. Instrução No 016/08- Critérios para o funcionamento da SALA DE RECURSOS, na área de Altas Habilidades /Superdotação, para a Educação Básica - SUED/SEED. http://www.nre.seed.pr.gov.br/londrina/arquivos/File/instrucao16SRAHSD.pdf acesso em: 08 mai.2020.

PARANÁ. Secretaria de Estado da Educação. Superintendência da Educação. Departamento de Educação Especial e Inclusão Educacional. Educação especial e inclusão educacional oito anos de gestão, 2003/2010 / Secretaria de Estado da Educação. Superintendência da Educação. Departamento de Educação Especial e Inclusão Educacional. - Curitiba: SEED - PR., 2010. - 450 p. Disponível em : http://www.educadores.diaadia.pr.gov.br/arquivos/File/ed_especial/relatoriodeein 200320 10.pdf acesso em: 10 out.2019

PARANÁ. Secretaria de Estado da Educação Superintendência da Educação. Instrução No 010/11- Estabelece critérios para o funcionamento da SALA DE RECUROS MULTIFUNCIONAL TIPO I - para a Educação Básica na Área das Altas Habilidades/Superdotação. Disponível em: http://diaadiaeducacao.pr.gov.br Acesso em 08 mai. 2019.

PARANÁ. Conselho Estadual de Educação. Deliberação n. ${ }^{\circ}$ 02/2016 de 15 de setembro de 2016. Dispõe sobre as Normas para a Modalidade Educação Especial no Sistema Estadual de Ensino do Paraná. Curitiba, 2016. Disponível em: www.cee.pr.gov.br. Acesso em: 19 jun. 2020.

PÉREZ, S. G. P. B. A identificação das altas habilidades/superdotação sob uma perspectiva multidimensional. Revista Educaşão Especial, Santa Maria, v. 22, n. 35, set./dez. 2009.

PÉREZ, S. G. P. B.; FREITAS, S. N. Encaminhamentos pedagógicos com alunos com Altas Habilidades/Superdotação na educação básica: o cenário brasileiro. Educar em Revista, Curitiba, Brasil, n. 41, p. 109-124, jul./set. 2011. Disponível em: https://www.scielo.br/pdf/er/n41/08.pdf. Acesso em: 15 mar. 2020.

POCINHO, M. Superdotação: Conceitos e Modelos De Diagnóstico e Intervenção Psicoeducativa. Revista Brasileira de Educação Especial, Marília, v. 15, n. 1, p. 3-14, 2009. Disponível em: http://www.scielo.br/pdf/rbee/v15n1/02.pdf. Acesso em: 12 de mar. 2019. 
RIBEIRO, O. L. C. Documento Técnico $n^{\circ} 01$ (modalidade produto de consultoria) Organização das Nações Unidas, para Educação, a Ciência e a Cultura (UNESCO), SECADI/MEC, 2017.

VYGOTSKY, L. S. Pensamento e Linguagem. São Paulo: Martins Fontes, 1991.

RECEBIDO: $14 / 12 / 2020$

APROVADO: $30 / 08 / 2021$

RECEIVED: $12 / 14 / 2020$

APPROVED: 08/30/2021

RECIBIDO: $14 / 12 / 2020$

APROBADO: $30 / 08 / 2021$ 